\title{
Inativação bacteriana e sensorialidade em bebidas formuladas a partir de extrato reconstituído de Ocimum gratissimum L. (Alfavaca) - Labiatae - (Lamiaceae)
}

\author{
Bacterial inactivation and sensory analysis in drink formulations prepared with \\ Ocimum gratissimum L. ("African basil") - Labiatae - (Lamiaceae) reconstituted extract
}

Marcelo Gonzalez PASSOS ${ }^{1}$, Heloisa Helena CARVALHO ${ }^{1}$, José Maria WIEST ${ }^{1 *}$

\section{Resumo}

A partir da formulação de quatro bebidas, duas alcoólicas e duas não alcoólicas, com e sem açúcar, respectivamente, e do extrato reconstituído (alcoolatura/planta verde) de Ocimum gratisimum L. ("alfavacão", "alfavaca", "alfavaca-cravo") - Labiatae - (Lamiaceae) em diferentes concentrações (5, 15 e 30\%), foi determinada, através de testes de suspensão em sistema de tubos múltiplos, a intensidade de atividade de inativação bacteriana (IINAB/bactericidia), sobre Salmonella Enteritidis (ATCC 11076), bem como a aceitabilidade/preferência sensorial por escala hedônica destes quatro produtos. Todas as formulações apresentaram atividade bactericida para Salmonella Enteritidis, diretamente proporcional às concentrações do extrato e ao tempo de exposição da bactéria às bebidas, destacando-se, neste sentido, a formulação não alcoólica com açúcar. Na análise sensorial, a preferência aumentou com o decréscimo da concentração de extrato de Ocimum gratissimum na formulação. A bebida não alcoólica com açúcar, na concentração de 5\% de extrato, destacou-se na preferência/aceitabilidade.

Palavras-chave: análise de bebidas; inativação bacteriana; sensorialidade em bebidas.

\begin{abstract}
The activity intensity of bacterial inactivation (IINAB/bactericidie) on Salmonella Enteritidis (ATCC 11076) was determined in four drink formulations, two alcoholic and two no-alcoholic, with and without sugar, respectively, and in the reconstituted extract (alcoholature/green plant) of Ocimum gratissimum L. (African basil) - Labiatae - (Lamiaceae) at different concentrations (5, 15, and 30\%) through suspension tests in multiple tube system. The acceptability/sensory preference of these four products was also determined using a hedonic scale. The bactericidal activity of all formulations against Salmonella Enteritidis was found to be directly proportional to the extract concentrations and the exposure time of the bacterium in the beverages, especially the non-alcoholic formulation with sugar. In the sensorial analysis, the preference increased with the decrease of the extract concentration of Ocimum gratissimum. The non-alcoholic beverage with sugar received the highest preference/acceptability score for the extract concentration of $5 \%$.

Keywords: drink evaluation; bacterial inactivation; drink sensory analysis.
\end{abstract}

\section{Introdução}

A busca por alimentos seguros, livres de microrganismos patogênicos, tem sido uma preocupação de órgãos governamentais e dos consumidores. Neste sentido, diversas pesquisas vêm sendo desenvolvidas com plantas utilizadas na medicina popular e na gastronomia tradicional, avaliando suas atividades bactericidas e fungicidas (AHN; GRÜN; MUSTAPHA, 2007; MOREIRA et al., 2005; NGUEFACK et al., 2004; SAHIN et al., 2004; TEPE et al., 2004; JIROVETSZ et al., 2003; SAĞDIÇ; ÖZCAN, 2003; HAMMER; CARSON; RILEY, 1999).

O gênero Ocimum pertence à família Labiatae (Lamiaceae), possuindo 30 espécies de ervas que são encontradas em regiões tropicais e subtropicais. Ocimum gratissimum L. é uma planta que possui aroma forte e agradável, popularmente chamado de "alfavacão", "alfavaca" e "alfavaca-cravo" com origem no oriente, subespontâneo em todo o Brasil e do qual existem diversos quimiotipos. Várias espécies de Ocimum são plantas classicamente fornecedoras de óleos essenciais, largamente utilizados como temperos de pratos especiais e aromatizantes de licores e de perfumes finos (LORENZI; MATOS, 2002).

Diferentes autores comparam as atividades bactericida e fungicida de plantas com indicativo medicinal ou condimentar, incluindo Ocimum gratissimum (FARIA et al., 2006; NGUEFACK; BUDDE; JAKOBSEN, 2004; NAKAMURA et al., 2004; SARTORATTO et al., 2004; ORAFIDIYA et al., 2001; NAKAMURA et al., 1999). Chah (2006) avaliou a atividade antibacteriana de plantas medicinais sobre $S$. aureus e E. coli, não encontrando atividade antibacteriana no extrato de Ocimum gratissimum. Nguefack et al. (2004) testaram a atividade antifúngica sobre agentes degradantes e produtores

Recebido para publicação em 28/4/2008

Aceito para publicação em 16/5/2009 (003466)

1 Programa de Pós-Graduação em Ciência e Tecnologia de Alimentos, Instituto de Ciências e Tecnologia de Alimentos, Universidade Federal do Rio Grande do Sul - UFRGS,

Campus do Vale, Av. Bento Gonçalves, 9500, CP 15090, CEP 91505-970, Porto Alegre - RS, Brasil, E-mail: jmwiest@ufrgs.br

${ }^{*}$ A quem a correspondência deve ser enviada 
de micotoxina, sugerindo o uso de Ocimum gratissimum, na formulação de bebidas não alcoólicas.

Este trabalho tem como objetivo avaliar a Intensidade de Atividade de Inativação Bacteriana (IINAB/bactericidia) de bebidas alcoólica e não alcoólica, na presença ou ausência de açúcar, respectivamente, formuladas a partir de extrato reconstituído de Ocimum gratisimum (alcoolatura/planta verde) sobre Salmonella Enteritidis (ATCC 11076), bem como determinar, através de análise sensorial, a aceitabilidade/ preferência destes produtos.

\section{Material e métodos}

\subsection{Coleta da planta e elaboração do extrato reconstituído}

A planta Ocimum gratissimum foi acessada em propriedade agroecológica familiar em Parque Eldorado, Município de Eldorado do Sul, região metropolitana de Porto Alegre - RS, Brasil (coordenadas de $30^{\circ} 05^{\prime} \mathrm{S}$ e $51^{\circ} 40^{\prime} \mathrm{W}$ ), constituindo-se de um pool de partes vegetativas e reprodutivas de exemplares subespontâneos e ruderais. Nesta propriedade, segundo a escala ACFOR de Kent e Coker (1992), Ocimum gratissimum se classifica na categoria de "frequente". Aplicando-se a escala de sociabilidade de Braun-Blanquet (1979), a planta se apresentava em pequenos grumos ou tufos de indivíduos não cultivados.

O material colhido foi herborizado segundo Ming (1996) e catalogado pela bióloga Silvia Marodin (CRBio/RS no 17268), sendo a duplicata botânica incorporada ao Herbário do Departamento de Botânica, do Instituto de Biociências, da Universidade Federal do Rio Grande do Sul, recebendo número de registro 150160 .

Talos, folhas e flores da planta foram submetidos ao processo de extração alcoólica (alcoolatura/planta fresca), para obtenção do extrato reconstituído, segundo Farmacopéia (1959). As amostras vegetais recém-colhidas foram trituradas grosseiramente e colocadas em álcool etílico, de cereais, a $96^{\circ} \mathrm{GL}$, na proporção de $400 \mathrm{~g}$ de planta para $1000 \mathrm{~mL}$ de álcool. Após um período de 15 dias, o extrato alcoólico foi submetido à destilação fracionada sob pressão reduzida em sistema rotavapor, desprezando-se a porção alcoólica e reidratando-se o extrato resultante com água destilada estéril, reconstituindo-se as concentrações iniciais da planta. Esta solução foi utilizada como base para formulação das bebidas.

\subsection{Preparação das bebidas}

As bebidas foram formuladas a partir do extrato reconstituído da planta Ocimum gratissimum nas concentrações de 5, 15 e 30\%. Para cada uma das concentrações de extrato foram preparados quatro tipos de formulações (Figura 1), a saber: bebida alcoólica com presença de açúcar (aperitivo doce/“I”); bebida alcoólica com ausência de açúcar (aperitivo amargo/“II”); bebida não alcoólica com presença de açúcar (aperitivo doce/“III”); e bebida não alcoólica com ausência de açúcar (aperitivo amargo/“IV”).

Foi realizado ensaio preliminar para a determinação de teor alcoólico, utilizado nas bebidas, que não interferisse na atividade bactericida posteriormente testada. As concentrações avaliadas foram elaboradas com álcool etílico, de cereais, a $96^{\circ} \mathrm{GL}$, em água destilada estéril, nas graduações alcoólicas, (\%/v) a $20{ }^{\circ} \mathrm{C}$ de: 0,0 (branco); 0,$5 ; 5,0 ; 10,0 ; 15,0 ; 20,0 ; 25,0$; 30,$0 ; 35,0 ; 40,0 ; 45,0 ; 50,0 ;$ e 54,0. Em $5 \mathrm{~mL}$ de cada uma destas concentrações, foram inoculados $500 \mu \mathrm{L}$ de $S$. Enteritidis (ATCC 11076) com 1,27 × 109 UFC.mL mL $^{-1}$. Após 24 horas de exposição em incubação aeróbia a $37^{\circ} \mathrm{C}$, foram transferidas alíquotas de cada concentração testada, através da técnica de microgota (ROMEIRO, 2007), para placas de Petri, contendo meio de cultura Plate Count Agar (PCA, ACUMEDIA ${ }^{\circledR}$ ), efetivando-se a avaliação final de crescimento bacteriano, novamente após 24 horas de incubação aeróbia a $37^{\circ} \mathrm{C}$. Este procedimento foi repetido para os tempos de exposição de 48, 72 e 144 horas. A graduação alcoólica definida pelo teste como inócua ao crescimento de Salmonella foi de $5 \%$ v, sendo adotada como constante na formulação das bebidas em estudo.

\subsection{Inóculo bacteriano}

Para o desenvolvimento do teste de suspensão, foi utilizada amostra padrão American Type Culture Colletion (ATCC) de

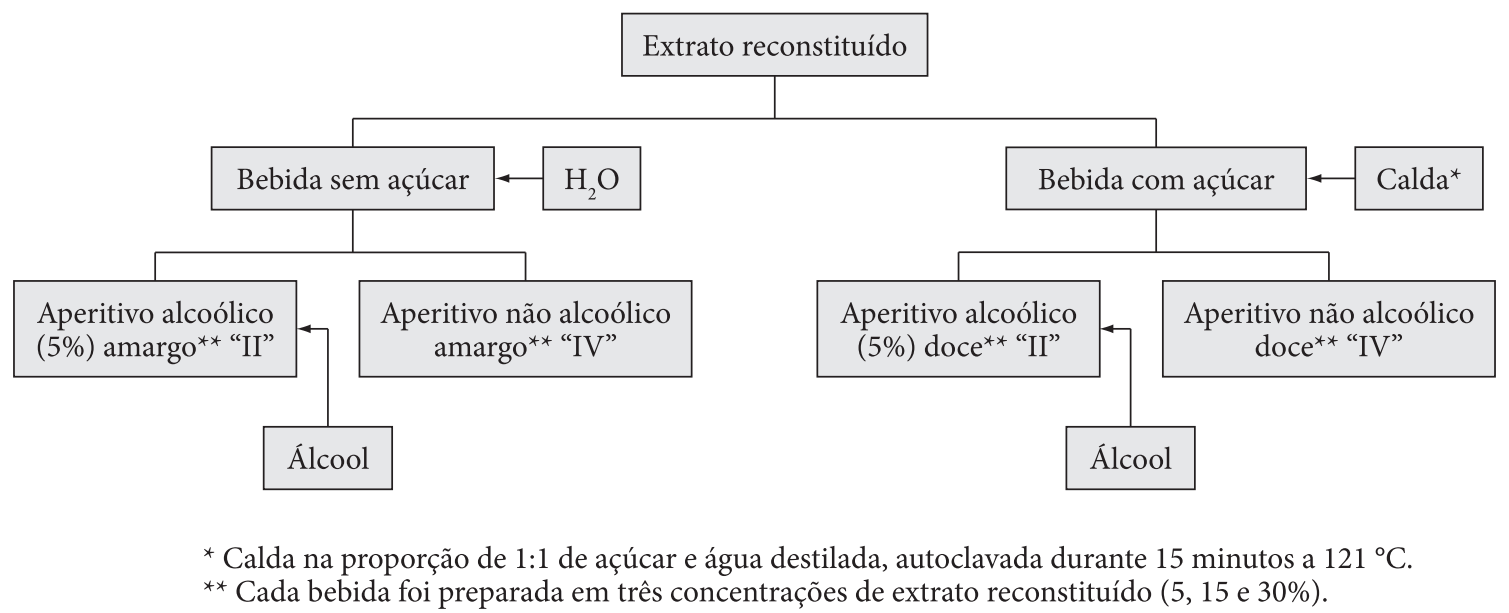

Figura 1. Fluxograma de elaboração dos quatro tipos de bebidas (aperitivos). 
S. Enteritidis (ATCC 11076), proveniente da coleção-bacterioteca do Laboratório de Higiene de Alimentos do Instituto de Ciências e Tecnologia de Alimentos da Universidade Federal do Rio Grande do Sul - UFRGS. A amostra foi reativada em meio de cultura Brain Heart Infusion (BHI, OXOID ${ }^{\circ}$ ) a $37^{\circ} \mathrm{C}$ por um período de 18 a 24 horas de incubação aeróbia, com o objetivo de atingir uma concentração $\geq 1,0 \times 10^{8} \mathrm{UFC} \cdot \mathrm{mL}^{-1}$, através de diluições seriais logarítmicas (AVANCINI, 2002). A avaliação da concentração inicial foi realizada através da técnica da microgota (ROMEIRO, 2007) e a contagem de microrganismos viáveis, concretizada em placas de Petri contendo meio de cultura Plate Count Agar $\left(\mathrm{PCA}^{\circledR}\right)$. Foram realizadas diluições seriadas, a partir do inóculo, transferindo-se $1 \mathrm{~mL}$ deste para tubos de ensaio contendo $9 \mathrm{~mL}$ de água peptonada $0,1 \%$ para obter a diluição $10^{-1}$. Este procedimento foi realizado sucessivamente até a diluição $10^{-8}$, para definir a melhor diluição de contagem. Para cada diluição, foram transferidas três gotas das suspensões para as placas, utilizando-se micropipetas de $15 \mu \mathrm{L}$, e a leitura foi realizada em 24 horas de incubação aeróbia a $37^{\circ} \mathrm{C}$. O valor final considerado como UFC.mL $\mathrm{mL}^{-1}$ constituiu a média das contagens das gotas triplicadas, avaliadas biometricamente segundo Cavalli-Sforza (1974).

\subsection{Teste de suspensão}

Para avaliação da intensidade da atividade antibacteriana presente nos quatro tipos de bebidas formuladas com extrato reconstituído de Ocimum gratissimun, lida como intensidade de atividade de inativação bacteriana (IINAB), utilizou-se o teste de suspensão, com base na técnica do sistema de tubos múltiplos, modificada por Avancini (2002), acrescido dos desinibidores bacterianos referidos por Andrade e Macêdo (1996), Reybrouck (1979, 1998), buscando, desta maneira, garantir a preditividade dos resultados de isolamentos negativos interpretados como bactericidia verdadeira (CORTES, 1993). Todas as formulações, a partir do extrato reconstituído da planta (em concentrações de 5, 15 e 30\%), foram confrontadas com oito diluições seriais logarítmicas $\left(10^{1}\right.$ a $10^{8}$ UFC.mL $\left.L^{-1}\right)$ do inóculo de Salmonella ativada a partir da bacterioteca. A sensibilidade ou resistência das diferentes diluições de Salmonella, confrontadas com o extrato reconstituído em suas diferentes concentrações nas bebidas formuladas, foi verificada através da presença ou ausência de bactérias viáveis em alíquotas transferidas de todos os tubos, por alça bacteriológica calibrada $(0,05 \mathrm{~mL})$, após $24,48,72$ e 144 horas de incubação aeróbia a $37^{\circ} \mathrm{C}$, a tubos de ensaio contendo $5 \mathrm{~mL}$ de meio de cultura Brain Heart Infusion (BHI, OXOID $^{\circledR}$ ). A seguir, foram incubadas por sua vez, durante 24 horas em aerobiose a $37^{\circ} \mathrm{C}$, efetivando-se, finalmente, a avaliação de crescimento bacteriano ou de bactericidia/ inativação.

Os resultados do confronto de Salmonella com as diferentes formulações de bebidas foram representados por variáveis ordinais arbitrárias (Tabela 1), que assumiram valores de 8 (oito) a 0 (zero), indicando a intensidade da atividade de inativação bacteriana das bebidas.
Tabela 1. Valores ordinais arbitrários de intensidade de atividade atribuídos à variável Intensidade de Atividade de Inativação Bacteriana/bactericidia (IINAB) e suas correspondentes diluições e doses infectantes dos inóculos.

\begin{tabular}{ccc}
\hline $\begin{array}{c}\text { Variáveis ordinárias de } \\
\text { intensidade de atividade }\end{array}$ & $\begin{array}{c}\text { UFC.mL } \\
\text { de inóculo inativadas }\end{array}$ & $\begin{array}{c}\text { UFC.mL } \\
\text { infectantes inativadas }\end{array}$ \\
\hline 0 & n.a & n.a \\
1 & $10^{-8}$ & $10^{0}$ \\
2 & $10^{-7}$ & $10^{1}$ \\
3 & $10^{-6}$ & $10^{2}$ \\
4 & $10^{-5}$ & $10^{3}$ \\
5 & $10^{-4}$ & $10^{4}$ \\
6 & $10^{-3}$ & $10^{5}$ \\
7 & $10^{-2}$ & $10^{6}$ \\
8 & $10^{-1}$ & $10^{7}$ \\
\hline
\end{tabular}

\subsection{Análise sensorial}

Para a análise sensorial foi utilizada a escala hedônica para avaliação de preferência e aceitabilidade das bebidas (aperitivos) por 27 provadores não treinados (DUTCOSKY, 1996). Para tal foi utilizada a escala de 9 (nove) pontos, variando do "desgosto muitíssimo" ao "gosto muitíssimo". A escala hedônica foi aplicada em dias diferentes agrupando as bebidas com açúcar e sem açúcar, para que os provadores não favorecessem uma bebida em detrimento de outra e para evitar também a fadiga sensorial dos provadores.

\subsection{Análise estatística}

Os resultados do teste de escala hedônica e do teste de suspensão foram tratados através do programa de análises estatísticas Sisvar 5.0 (UNIVERSIDADE FEDERAL DE LAVRAS, 2007), sendo realizados a análise de variância (Anova) e o teste de Tukey.

\section{Resultados e discussão}

\subsection{Inativação de Salmonella através do teste de suspensão}

O Quadro 1 demonstra a síntese dos resultados da atividade antibacteriana de extratos reconstituídos (alcoolatura/planta verde) de Ocimum gratissimum, em quatro formulações de bebidas com a presença e ausência de álcool e a presença e ausência de açúcar, respectivamente, sobre $S$. Enteritidis (ATCC 11076), relacionando os seguintes fatores: tempo de confrontação (exposição) da bactéria na bebida $(5,15,30$ e 60 minutos), tempo de incubação (24, 48, 72 e 144 horas), concentração final do extrato reconstituído.

Quando avaliados os tempos de exposição da bactéria nas bebidas, independentemente das demais variáveis manipuladas (Tabela 2), estes apresentaram diferenças significativas entre si. Nesta Tabela, o tempo de exposição de 60 minutos apresentou valor superior aos demais tempos, seguido de 30, 15 e 5 minutos. A atividade antibacteriana apresentou-se diretamente proporcional ao tempo de exposição, ou contato, ao extrato da planta. Autores como Sartorrato et al. (2004), Nakamura et al. (1999) e Akinyemi et al. (2004) também 
descrevem atividade bactericida de extratos de Ocimum gratissimum sobre $S$. Enteritidis, porém utilizando diferentes técnicas de avaliação.

A Tabela 3 apresenta a avaliação dos tempos de incubação da bactéria nas bebidas. Independentemente das demais variáveis manipuladas, estes não apresentaram diferenças significativas entre si. O tempo de incubação de 24 horas apresentou valor superior aos demais tempos, e os restantes apresentaram os mesmos valores.

Quando avaliadas as diferentes concentrações de Ocimum gratissimum nas bebidas, independentemente das demais variáveis manipuladas, estas apresentaram diferenças significativas entre si (Tabela 4). A concentração de 30\% apresentou valor superior às demais concentrações, pois à medida que aumentou a concentração de extrato aumentou a atividade antibacteriana sobre a $S$. Enteritidis. Estes resultados encontram-se em concordância com trabalhos de outros pesquisadores com a planta em questão (SARTORRATO et al., 2004; AKINYEMI et al., 2004; NAKAMURA et al., 1999).

Avaliando os tipos de bebidas quanto à presença $\mathrm{e}$ ausência de álcool, independentemente das demais variáveis manipuladas, estas apresentaram diferenças significativas entre si (Tabela 5). A bebida não alcoólica apresentou valor superior à bebida alcoólica. Estes resultados reforçam a não interveniência antibacteriana do álcool presente em duas das formulações estudadas, conforme já fora determinado em testes anteriores.

Na Tabela 6, quando avaliados os tipos de bebidas quanto à presença e ausência de açúcar, independentemente das demais variáveis manipuladas, estas apresentaram diferenças significativas entre si. A bebida com açúcar apresentou valor

Quadro 1. Intensidade da Atividade Inativação Bacteriana/bactericidia (IINAB) de diferentes concentrações de extrato reconstituído (alcoolatura/ planta verde) de Ocimum gratissimum-("alfavacão", "alfavaca", "alfavaca-cravo") - Labiatae (Lamiaceae) sobre S. Enteritidis (ATCC 11076) determinada através de teste de suspensão, em bebidas formuladas na presença e ausência de álcool e de açúcar, respectivamente, segundo diferentes tempos de incubação e de confronto.

\begin{tabular}{|c|c|c|c|c|c|c|c|c|c|c|c|c|c|}
\hline & & \multicolumn{4}{|c|}{ Extrato $30 \%$} & \multicolumn{4}{|c|}{ Extrato $15 \%$} & \multicolumn{4}{|c|}{ Extrato $5 \%$} \\
\hline & Bebidas & Alcoólica & Alcoólica & $\begin{array}{c}\text { Não } \\
\text { alcoólica }\end{array}$ & $\begin{array}{c}\text { Não } \\
\text { alcoólica }\end{array}$ & Alcoólica & Alcoólica & $\begin{array}{c}\text { Não } \\
\text { alcoólica }\end{array}$ & $\begin{array}{c}\text { Não } \\
\text { alcoólica }\end{array}$ & Alcoólica & Alcoólica & $\begin{array}{c}\text { Não } \\
\text { alcoólica }\end{array}$ & $\begin{array}{c}\text { Não } \\
\text { alcoólica }\end{array}$ \\
\hline $\begin{array}{c}\text { Tempo de } \\
\text { incubação } \\
\text { (horas) }\end{array}$ & $\begin{array}{l}\text { Tempo de } \\
\text { confronto } \\
\text { (minutos') }\end{array}$ & $\begin{array}{l}\text { Com } \\
\text { açúcar }\end{array}$ & $\begin{array}{c}\text { Sem } \\
\text { açúcar }\end{array}$ & $\begin{array}{l}\text { Com } \\
\text { açúcar }\end{array}$ & $\begin{array}{c}\text { Sem } \\
\text { açúcar }\end{array}$ & $\begin{array}{c}\text { Com } \\
\text { açúcar }\end{array}$ & $\begin{array}{c}\text { Sem } \\
\text { açúcar }\end{array}$ & $\begin{array}{l}\text { Com } \\
\text { açúcar }\end{array}$ & $\begin{array}{c}\text { Sem } \\
\text { açúcar }\end{array}$ & $\begin{array}{c}\text { Com } \\
\text { açúcar }\end{array}$ & $\begin{array}{c}\text { Sem } \\
\text { açúcar }\end{array}$ & $\begin{array}{l}\text { Com } \\
\text { açúcar }\end{array}$ & $\begin{array}{c}\text { Sem } \\
\text { açúcar }\end{array}$ \\
\hline \multirow[t]{4}{*}{24} & 5 & 4 & 0 & 5 & 0 & 0 & 0 & 2 & 2 & 0 & 0 & 1 & 1 \\
\hline & 15 & 6 & 4 & 5 & 6 & 0 & 3 & 2 & 2 & 0 & 0 & 1 & 1 \\
\hline & 30 & 6 & 5 & 6 & 6 & 3 & 3 & 2 & 2 & 2 & 0 & 1 & 0 \\
\hline & 60 & 7 & 6 & 7 & 7 & 4 & 3 & 2 & 2 & 2 & 1 & 1 & 0 \\
\hline \multirow[t]{4}{*}{48} & 5 & 4 & 0 & 5 & 0 & 0 & 0 & 2 & 2 & 0 & 0 & 0 & 0 \\
\hline & 15 & 6 & 4 & 5 & 6 & 0 & 3 & 2 & 2 & 0 & 0 & 0 & 0 \\
\hline & 30 & 6 & 5 & 6 & 6 & 2 & 3 & 2 & 2 & 0 & 0 & 0 & 0 \\
\hline & 60 & 7 & 6 & 7 & 7 & 2 & 3 & 2 & 2 & 0 & 1 & 0 & 0 \\
\hline \multirow[t]{4}{*}{72} & 5 & 4 & 0 & 5 & 0 & 0 & 0 & 2 & 2 & 0 & 0 & 0 & 0 \\
\hline & 15 & 6 & 4 & 5 & 6 & 0 & 3 & 2 & 2 & 0 & 0 & 0 & 0 \\
\hline & 30 & 6 & 5 & 6 & 6 & 2 & 3 & 2 & 2 & 0 & 0 & 0 & 0 \\
\hline & 60 & 7 & 6 & 7 & 7 & 2 & 3 & 2 & 2 & 0 & 1 & 0 & 0 \\
\hline \multirow[t]{4}{*}{144} & 5 & 4 & 0 & 5 & 0 & 0 & 0 & 2 & 2 & 0 & 0 & 0 & 0 \\
\hline & 15 & 6 & 4 & 5 & 6 & 0 & 3 & 2 & 2 & 0 & 0 & 0 & 0 \\
\hline & 30 & 6 & 5 & 6 & 6 & 2 & 3 & 2 & 2 & 0 & 0 & 0 & 0 \\
\hline & 60 & 7 & 6 & 7 & 7 & 2 & 3 & 2 & 2 & 0 & 1 & 0 & 0 \\
\hline
\end{tabular}

Tabela 2. Avaliação da atividade antibacteriana de extrato reconstituído de Ocimum gratissimum sobre a S. Enteritidis (ATCC 11076) segundo tempo de confrontação (exposição), independente dos fatores: tempo de incubação, concentração do extrato, presença ou ausência de álcool e presença e ausência de açúcar nas bebidas.

\begin{tabular}{cc}
\hline Tempo de confrontação (minuto) & Número arbitrário \\
\hline 5 & $1,13^{\text {a* }}$ \\
15 & $2,38^{\mathrm{b}}$ \\
30 & $2,75^{\mathrm{c}}$ \\
60 & $3,19^{\mathrm{d}}$ \\
\hline
\end{tabular}

Letras minúsculas diferentes sobrescritas (a) na mesma coluna indicam diferenças significativas entre os tempos de confrontação (exposição) para a análise de variância (Anova) e teste de Tukey $(\mathrm{p}<0,05)$.
Tabela 3. Avaliação da atividade antibacteriana de extrato reconstituído de Ocimum gratissimum sobre a S. Enteritidis (ATCC 11076) segundo tempo de incubação, independente dos fatores: tempo de confrontação (exposição), concentração do extrato, presença ou ausência de álcool e presença e ausência de açúcar nas bebidas.

\begin{tabular}{cc}
\hline Tempo de incubação (hora) & Número arbitrário \\
\hline $72^{\star}$ & $2,29^{\mathrm{a}}$ \\
114 & $2,29^{\mathrm{a}}$ \\
48 & $2,29^{\mathrm{a}}$ \\
24 & $2,56^{\mathrm{a}}$ \\
\hline
\end{tabular}

Letras minúsculas diferentes sobrescritas (a) na mesma coluna indicam diferenças significativas entre os tempos de incubação para a análise de variância (Anova) e teste de Tukey $(\mathrm{p}<0,05)$. 
Tabela 4. Avaliação da atividade antibacteriana sobre a $S$. Enteritidis (ATCC 11076) segundo as concentrações de extrato de Ocimum gratissimum, independente dos fatores: tempo de confrontação (exposição), tempo de incubação, presença ou ausência de álcool nas bebidas e presença e ausência de açúcar nas bebidas.

\begin{tabular}{cc}
\hline Concentrações de extrato de Ocimum gratissimum & Número arbitrário \\
\hline $5^{\star}$ & $0,22^{\mathrm{a}}$ \\
$15^{\star}$ & $1,86^{\mathrm{b}}$ \\
$30^{\star}$ & $5,00^{\mathrm{c}}$ \\
\hline
\end{tabular}

Letras minúsculas diferentes sobrescritas (a) na mesma coluna indicam diferenças significativas entre concentrações de extrato de Ocimum gratissimum para a análise de variância (Anova) e teste de Tukey $(\mathrm{p}<0,05)$.

Tabela 5. Avaliação da atividade antibacteriana sobre a $S$. Enteritidis (ATCC 11076) segundo a presença e ausência de álcool, independente dos fatores: tempo de confrontação (exposição), tempo de incubação, concentração de extrato de Ocimum gratissimum e presença e ausência de açúcar nas bebidas.

\begin{tabular}{cc}
\hline Presença e ausência de álcool & Número arbitrário \\
\hline Alcoólica & $2,24^{\mathrm{a}}$ \\
Não alcoólica & $2,48^{\mathrm{b}}$ \\
\hline
\end{tabular}

Letras minúsculas diferentes sobrescritas (a) na mesma coluna indicam diferenças significativas entre as bebidas alcoólica e não alcoólica para a análise de variância (Anova) e teste de Tukey $(\mathrm{p}<0,05)$.

Tabela 6. Avaliação da atividade antibacteriana sobre a $S$. Enteritidis (ATCC 11076) segundo a presença e ausência de açúcar, independente dos fatores: tempo de confrontação (exposição), tempo de incubação, concentração de extrato de Ocimum gratissimum e presença e ausência de álcool nas bebidas.

\begin{tabular}{cc}
\hline Presença e ausência de açúcar & Número arbitrário \\
\hline Sem $^{\star}$ & $2,19^{\mathrm{a}}$ \\
Com & $2,53^{\mathrm{b}}$ \\
\hline
\end{tabular}

Letras minúsculas diferentes sobrescritas (a) na mesma coluna indicam diferenças significativas entre as bebidas com e sem açúcar para a análise de variância (Anova) e teste de Tukey $(\mathrm{p}<0,05)$.

superior à bebida sem açúcar. Uma possível hipótese para esta observação poderia ser a interveniência da pressão osmótica mais elevada contribuindo com a atividade bactericida, embora, segundo Schliesser e Strauch (1981), a concentração de açúcar, por sua vez, pode funcionar como um protetor bacteriano, diminuindo a eficácia de soluções antimicrobianas em geral.

Ao analisar a concentração de $5 \%$ de extrato da planta, não foi observada diferença significativa entre os tempos de exposição (Tabela 7). Na concentração de 15\% de extrato, não houve diferenças significativas entre os tempos de exposição de 15 e 30 minutos e entre 30 e 60 minutos. Já na concentração de $30 \%$ de extrato, não houve diferenças significativas entre os tempos de exposição de 15 e 30 minutos. Quando avaliadas as concentrações de extrato, individualmente em cada um dos tempos de exposição, houve diferenças significativas em todos eles. Os resultados são superiores à medida que aumentam os tempos de exposição e as concentrações de extrato de Ocimum gratissimum.
Tabela 7. Avaliação da atividade antibacteriana sobre a $S$. Enteritidis (ATCC 11076) segundo a correlação entre o tempo de confrontação (exposição) e as concentrações de extrato de Ocimum gratissimum, independente dos fatores: tempo de incubação presença e ausência de açúcar nas bebidas e a presença e ausência de álcool nas bebidas.

\begin{tabular}{cccc}
\hline $\begin{array}{c}\text { Tempo de confrontação } \\
\text { (minuto) }\end{array}$ & \multicolumn{3}{c}{ Concentrações de extrato } \\
\cline { 2 - 4 } & $5 \%$ & $15 \%$ & $30 \%$ \\
\hline 5 & $0,13^{\mathrm{aA}}$ & $1,00^{\mathrm{aB}}$ & $2,25^{\mathrm{aC}}$ \\
15 & $0,13^{\mathrm{aA}}$ & $1,75^{\mathrm{bB}}$ & $5,25^{\mathrm{bC}}$ \\
30 & $0,19^{\mathrm{aA}}$ & $2,31^{\mathrm{bcB}}$ & $5,75^{\mathrm{bC}}$ \\
60 & $0,44^{\mathrm{aA}}$ & $2,38^{\mathrm{cB}}$ & $6,75^{\mathrm{cC}}$ \\
\hline
\end{tabular}

Letras minúsculas diferentes sobrescritas ( $\left.{ }^{a}\right)$ na mesma coluna indicam diferenças significativas entre os diferentes tempos de confrontação e letras maiúsculas diferentes sobrescritas $\left({ }^{\mathrm{A}}\right)$ na mesma linha indicam diferenças significativas entre as diferentes concentrações de extrato de Ocimum gratissimum para a análise de variância (Anova) e teste de Tukey $(\mathrm{p}<0,05)$.

\subsection{Análise sensorial}

Quando avaliadas as bebidas quanto à concentração de extrato de Ocimum gratissimum, independentemente dos outros fatores, estas apresentaram diferenças significativas (Tabela 8). A concentração de extrato preferida foi a de 5\%, recebendo a avaliação da escala hedônica de "não desgostei nem gostei”. A concentração de 15\% de extrato apresentou avaliação de "desgostei ligeiramente" e a de 30\% de "desgostei moderadamente". Estes resultados podem ser explicados pela ação da bebida amarga, que, possivelmente, reduza a média de aceitabilidade das bebidas de forma geral.

A análise das bebidas quanto à presença e ausência de álcool, em relação às diferentes concentrações de extrato de Ocimum gratissimum descritas na Tabela 9, apresentou diferenças significativas nas bebidas não alcoólicas, quando comparadas somente às diferentes concentrações de extrato. A bebida não alcoólica com concentração de $5 \%$ foi superior na aceitabilidade (escala hedônica nas categorias "não desgostei nem gostei”), seguida de 15\% ("desgostei ligeiramente") e 30\% ("desgostei moderadamente"). Já nas bebidas alcoólicas, as concentrações de 15 e 30\% de extratos não apresentaram diferenças significativas. A bebida alcoólica com concentração de 5\% foi superior na aceitabilidade ("não desgostei nem gostei"), seguida de 15\% ("desgostei ligeiramente") e 30\% ("desgostei moderadamente"). Quando comparadas às bebidas alcoólicas e não alcoólicas em cada concentração de extrato individualmente, observou-se, na concentração de $5 \%$, diferença significativa, enquanto que nas concentrações de 15 e 30\% não houve diferença.

A análise das bebidas quanto à presença e ausência de açúcar em relação às diferentes concentrações de extrato de Ocimum gratissimum (Tabela 10) apresentou diferenças significativas nas bebidas com açúcar, quando comparadas somente as diferentes concentrações de extrato. A bebida açucarada com concentração de $5 \%$ foi superior na aceitabilidade ("gostei ligeiramente"), seguida de 15\% ("não desgostei nem gostei”) e 30\% ("desgostei ligeiramente"). Já nas bebidas sem açúcar, as concentrações de 15 e 5\% de extratos não apresentaram diferenças significativas. A bebida não açucarada com concentração de 5\% foi superior na aceitabilidade ("não desgostei nem gostei”), seguida de $15 \%$ 
Tabela 8. Avaliação das bebidas formuladas segundo a concentração de extrato de Ocimum gratissimum independente da presença e ausência de açúcar e presença e ausência de álcool.

\begin{tabular}{cc}
\hline Concentração de extrato (\%) & Aceitabilidade \\
\hline 30 & $3,60^{\mathrm{a}}$ \\
15 & $4,51^{\mathrm{b}}$ \\
5 & $5,40^{\mathrm{c}}$ \\
\hline
\end{tabular}

Letras minúsculas diferentes sobrescritas (a) na mesma coluna indicam diferenças significativas entre as concentrações de extrato de Ocimum gratissimum para a análise de variância (Anova) e teste de Tukey $(\mathrm{p}<0,05)$.

Tabela 9. Avaliação das bebidas formuladas segundo a concentração de extrato de Ocimum gratissimum correlacionada com a presença e ausência de álcool, independente da presença e ausência de açúcar.

\begin{tabular}{|c|c|c|}
\hline \multirow{2}{*}{$\begin{array}{c}\text { Concentração de extrato } \\
(\%)\end{array}$} & \multicolumn{2}{|c|}{ Bebida } \\
\hline & Alcoólica & Não alcoólica \\
\hline 30 & $3,67^{\mathrm{a}}$ & $3,54^{\mathrm{a}}$ \\
\hline 15 & $4,39^{\mathrm{ab}}$ & $4,63^{\mathrm{b}}$ \\
\hline 5 & $5,06^{\mathrm{b} *}$ & $5,74^{c *}$ \\
\hline
\end{tabular}

Letras minúsculas diferentes sobrescritas (a) na mesma coluna indicam diferenças significativas entre as diferentes concentrações de extrato reconstituído de 'nas bebidas e letras maiúsculas diferentes sobrescritas $\left({ }^{\mathrm{A}}\right)$ na mesma linha indicam diferenças significativas entre as diferentes bebidas: alcoólicas e não alcoólicas para a análise de variância (Anova) e teste de Tukey $(\mathrm{p}<0,05)$.

Tabela 10. Avaliação das bebidas formuladas segundo a concentração de extrato de Ocimum gratissimum correlacionada com a presença e ausência de açúcar, independente do fator de presença e ausência de álcool.

\begin{tabular}{cll}
\hline Concentração de extrato & \multicolumn{2}{c}{ Açúcar } \\
\cline { 2 - 3 }$(\%)$ & Com & Sem \\
\hline 30 & $4,09^{\mathrm{a} *}$ & $3,11^{\mathrm{a} *}$ \\
15 & $4,93^{\mathrm{b} *}$ & $4,09^{\mathrm{b} *}$ \\
5 & $5,96^{\mathrm{c}}$ & $4,83^{\mathrm{b}}$ \\
\hline
\end{tabular}

Letras minúsculas diferentes sobrescritas (a) na mesma coluna indicam diferenças significativas entre as diferentes concentrações de extratos reconstituídos de Ocimum gratissimum nas bebidas e letras maiúsculas diferentes sobrescritas $\left({ }^{\mathrm{A}}\right)$ na mesma linha indicam diferenças significativas entre as diferentes bebidas: com presença e ausência de açúcar para a análise de variância (Anova) e teste de Tukey $(\mathrm{p}<0,05)$.

("desgostei ligeiramente") e 30\% ("desgostei moderadamente"). Quando comparadas as bebidas com e sem açúcar, segundo cada concentração de extrato, individualmente, observaramse diferenças significativas em todos os extratos. As bebidas com açúcar em comparação às sem açúcar obtiveram valores numéricos de aceitabilidade superiores em todas as concentrações.

\section{Conclusões}

Nas condições dos experimentos, todas as bebidas apresentaram atividade bactericida frente a $S$. Enteritidis. A ação antissalmonela aumentou à medida que aumentaram as concentrações de extrato da planta na bebida e o tempo de exposição da bactéria às formulações de bebida. A bebida não alcoólica com a presença de açúcar apresentou a maior atividade bactericida sobre $S$. Enteritidis. Na análise sensorial, a preferência às bebidas cresceu com o decréscimo da concentração de extrato de Ocimum gratissimum. A preferida foi a que apresentou 5\% de concentração de extrato, não alcoólica e com presença de açúcar.

Os resultados indicam perspectivas de aplicação de extratos reconstituídos de Ocimum gratissimum no desenvolvimento de alimentos, pela sua ação bactericida e suas propriedades sensoriais. Dentre as bebidas, destaca-se a formulação sem álcool, licorosa, potencialmente direcionável à faixa de população abstêmia.

\section{Agradecimentos}

Ao CNPq pelo financiamento continuado.

\section{Referências bibliográficas}

AHN, J.; GRÜN, I. U.; MUSTAPHA, A. Effects of plant extracts on microbial growth, color change, and lipid oxidation in cooked beef. Food Microbiology, v. 24, n. 4, p. 7-14, 2007.

AKINYEMI, K. O. et al. Screening of some medicinal plants for anti salmonella activity. Journal of Herbal Pharmocother, v. 5, n. 1, p. 45-60, 2004.

ANDRADE, N. J. de; MACÊDO, J. A. B. de. Higienização na indústria de alimentos. São Paulo: Varela. 1996. 182p.

AVANCINI, C. A. M. Desinfecção em saúde e produção animal: bacteriostasia e bacteriocidia de Baccharis trimera (Less) D. C. Compositae - ("carqueja") frente a microrganismos entéricos e cutâneos. 1995. 100 p. Dissertação (Mestrado em Ciências Veterinárias) - Faculdade de Veterinária, Universidade Federal do Rio Grande do Sul, Porto Alegre, 1995.

AVANCINI, C. A. M. Saneamento aplicado em saúde e produção animal: etnografia, triagem da atividade antibacteriana de plantas nativas do Sul do Brasil e testes de avaliação do decocto de Hypericum caprifolioatum- Cham e Schlecht. Hypericaceae (Guttiferae) - ("escadinha"/"sinapismo") para uso como desinfetante e antisséptico. 2002. 309 p. Tese (Doutorado em Ciências Veterinárias) - Faculdade de Veterinária, Universidade Federal do Rio Grande do Sul, Porto Alegre, 2002.

BRAUN-BLANQUET, J. Fitossociologia: bases para el estudio de las comunidades vegetales. 1 ed. Madrid: Ed. M. Blume Ediciones, 1979. 820p.

CAVALLI-SFORZA, L. Biometrie: Grundzüge biologisch-medizinische Statistic. Stuttgart: Gustav Fisher, 1974. p. 201-204.

$\mathrm{CHAH}, \mathrm{K}$. F. et al. Antibacterial and wound healing properties of methanolic extracts of some Nigerian medicinal plants. Journal of Ethnopharmacology, v. 104, n. 1-2, p. 164-167, 2006.

CECCHI, H. M. Fundamentos téoricos e práticos em análise de alimentos. Campinas: Editora da Unicamp, 2001.

CORTES, J. de A. Epidemiologia: conceitos e princípios fundamentais. São Paulo: Varela, 1993.

GESELLSSCHAFT, D. V. Richtlinien zur Prüfung chemischer Desinfektionsmittel fur die Veterinärmedizin. In: SCHLIESSER, T.; STRAUCH, D. Desinfektion in Tierhaltung, Fleisch- und Milschwirtschaft. Stuttgart: Enke Verlag, 1981. 451 p.

DUTCOSKY, S. D. Análise sensorial de alimentos. Curitiba: Editora Champagnat,1996.

FARIA, T. J. et al. Antifungal Activity of Essential Oil Isolated from Ocimum gratissimum L. (eugenol chemotype) against Phytopathogenic Fungi. Brazilian archives of biology and technology, v. 49, n. 6, p. 867-871, 2006. 
FARMACOPÉIA dos Estados Unidos do Brasil: código farmacêutico brasileiro. 2 ed. São Paulo: Siqueira, 1959.

HAMMER, K. A.; CARSON, C. F.; RILEY, T. V. Antimicrobial activity of essential oils and other plant extracts. Journal Applied Microbiology, v. 86, n. 6, p. 985-990, 1999.

JIROVETZ, L. et al. Chemotaxonomical analysis of the essential oil aroma compounds of four different Ocimum species from southern India. European Food Research and Technology, v. 217, n. 2, p. 120-124, 2003.

KENT, M.; COKER, P. Vegetation description and analysis: a practical approach. London: Blackwell, 1992.

LORENZI, H.; MATOS, F. J. A. Plantas medicinais no Brasil: nativas e exóticas. Nova Odessa: Instituto Plantarum, 2002.

MING, L. C. Coleta de plantas medicinais. In: DI STASI, L. C. Plantas medicinais arte e ciência: um guia de estudo interdisciplinar. São Paulo: Editora UNESP, 1996. p. 69-86.

MOREIRA, M. R. et al. Inhibitory parameters of essential oils to reduce a foodborne pathogen. LWT - Food Science and Technology, v. 38, n. 5, p. 565-570, 2005.

NAKAMURA, C. V. et al. Antibacterial Activity of Ocimum gratissimum L. Essential Oil. Memórias do Instituto Oswaldo Cruz, v. 94, n. 5, p. 675-678, 1999.

NAKAMURA, C. V. et al. In vitro activity of essential oil from Ocimum gratissimum L. against four Candida species. Research in Microbiology, v. 155, n. 7, p. 579-586, 2004.

NGUEFACK, J. et al. Evaluation of five essential oils from aromatic plants of Cameroon for controlling food spoilage and mycotoxin producing fungi. International Journal of Food Microbiology, v. 94, n. 3, p. 329-334, 2004.

NGUEFACK, J.; BUDDE, B. B.; JAKOBSEN, M. Five essential oils from aromatic plants of Cameroon: their antibacterial activity and ability to permeabilize the cytoplasmic membrane of Listeria innocua examined by flow cytometry. Letters in Applied Microbiology, v. 39, n. 5, p. 395-400, 2004.

ORAFIDIYA, L. O. et al. The formulation of an effective topical antibacterial product containing Ocimum gratissimum leaf essential oil. International Journal of Pharmaceutics, v. 224, n. 1-2, p. 177-183, 2001.

REYBROUCK, G. Efficacy of inactivators against 14 disinfectant substances. Bakteriologie und Hygiene Zentralblatt: Abteilung Originale B, v. 68, n. 5-6, p. 480-492, 1979.

REYBROUCK, G. The testing of disinfectants. International Biodeterioration \& Biodegration, v. 41, n. 3-4, p. 269-272, 1998.

ROMEIRO, R. S. Técnica de microgota para contagem de células bacterianas viáveis em uma suspensão. Disponível em: $<\mathrm{http}: / /$ www.ufv.br/dfp/bac/uni9.pdf. >. Acesso em: 23 mar. 2007. Roteiro das aulas práticas.

SCHLIESSER, T.; STRAUCH, D. Desinfektion in Tierhaltung, Fleisch- und Milschwirtschaft. Stuttgart: Enke Verlag, 1981.

AĞDIÇ, O.; ÖZCAN, M. Antibacterial activity of Turkish spice hydrosols. Food Control, v.14, n. 3, p. 141-143, 2003.

SAHIN, F. et al. Biological activities of the essential oils and methanol extract of Origanum vulgare ssp. vulgare in the Eastern Anatolia region of Turkey. Food Control, v. 15, n. 7, p. 549-557, 2004.

SARTORATTO, A. et al. Composition and antimicrobial activity of essential oils from aromatic plants used in Brazil. Brazilian Journal of Microbiology, v. 35, n. 4, p. 275-280, 2004.

UNIVERSIDADE FEDERAL DE LAVRAS. SISVAR 5,0. Disponível em: < http://www.dex.ufla.br/ danielff/softwares.htm.>. Acesso em: 23 set. 2007.

TEPE, B. et al. Antimicrobial and antioxidative activities of the essential oils and methanol extracts of Salvia cryptantha (Montbret et Aucher ex Benth.) and Salvia multicaulis (Vahl). Food Chemistry, v. 84, n. 4 , p. 519-525, 2004. 